\title{
From Equations to Understanding
}

\author{
Linda A. Joyce
}

$\mathrm{T}$ The purpose of science is to generate understanding. Scientific research is the process of building that body of understanding. It involves phases that are descriptive, experimental, and finally, theoretical and quantitative (Figure 1). Nature is first observed, as the early botanical expeditions of the West record, or as recent publications of new bird species report. In this phase, observations are documented. A more quantitative step is taken when measurements of the natural world are made. How much plant biomass is produced during a growing season? Observations and measurements generate hypotheses about how the natural world functions. Experiments are used to test these hypotheses. For example, an experiment could test the hypothesis that plant biomass production increases under specified amounts of nitrogen and water. These observations and experimental results build theory-a set of scientifically-accepted principles that explain the dynamics of the natural world. As this body of understanding increases, it is quantified using statistics, mathematics, systems analysis, and computer science. For example, the relationship between rainfall, nitrogen availability, and plant biomass production could be expressed as a mathematical equation. Quantifying the theory helps to extend our understanding. And as the theory is applied, new questions are asked and the cycle begins again.

The development of theory in range science is valuable because it provides a framework to generate and test hypotheses and leads to explanations for observations. Good ecological

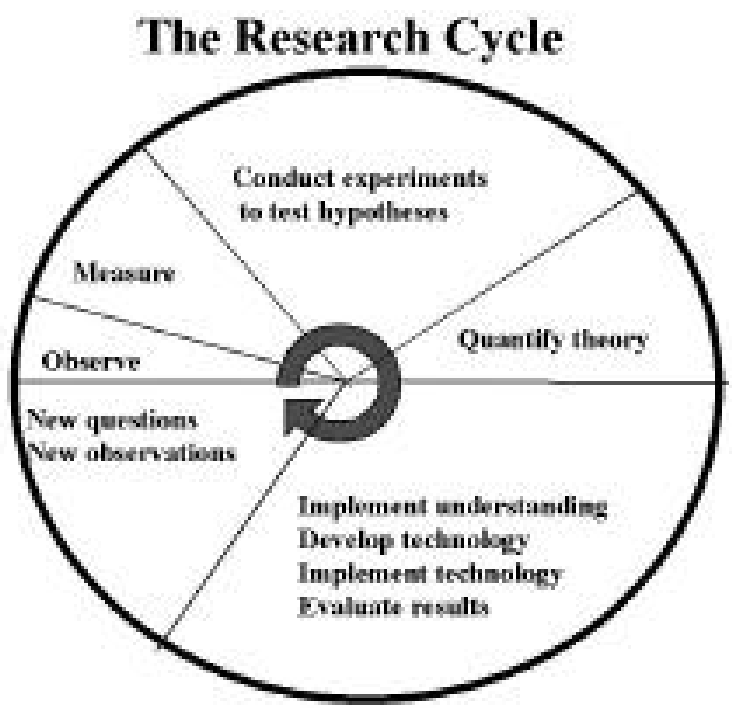

Figure. 1. The research cycle includes the phases of observation, ex perimentation, and the development of theory. The implementation of this theory often leads to new questions and another cycle through the research phases. theory is difficult to develop. Ecosystems have a diversity of organisms and processes that are difficult to model simply. Ecosystems are sensitive to what happened last year, or the year before, or maybe a hundred years ago. Theory may have unmeasurable concepts. Ethics or feasibility may limit field experimentation.

What do models have to do with theory? Models represent and simplify reality by showing the relationships between objects of a theory, the causal interactions, and the states of the systems (Pickett et al. 1994). Models help scientists cope with some of the problems of developing good theory. Models can be static, such as a diagram of a grass plant. Models can be system diagrams, with arrows indicating movement of nutrients or populations within a grassland. And, models can be analytical. The use of analytical models in generating understanding in range science is the focus of this paper.

\section{Analytical Models}

Analytical models are quantitative expressions of theory. They encompass numerical constants, a single equation, mathematical models (several equations), computer simulation models, and optimization models. In the broader arena of science, some examples of models are the speed of light in a vacuum $(299,792,458 \mathrm{~km}$ per second), simulation models used to make short-term weather forecasts or annual wildlife population estimates, and perhaps the most famous single equation: $\mathrm{E}=\mathrm{M}^{*} \mathrm{C}^{2}$.

Examples in range science include stocking rate equations and models predicting forage utilization based on leaf area index. More complicated, yet still relatively simple, are statetransition models of rangeland vegetation succession. Very complicated simulation models look at plant and animal productivity in grassland ecosystems as functions of many environmental variables.

Have models really helped to build the body of understanding we call range science? Some models, such as statistical models, have likely contributed significantly to range science. The Journal of Range Management is filled with many examples where statistical models have been used to identify significance or the lack of it in testable hypotheses. A recent example would be the study by Volesky et al (1999) where the authors use statistical models to conclude that neither leaf area index nor visual obstruction would be useful as direct predictors of total standing crop at individual sample locations on upland range sites in the Nebraska Sandhills. The controversy about the usefulness of models in range science seems to center more on simulation or computer models.

\section{Simulation Models in Range Science}

Early simulation models in range science were developed by scientists at Colorado State University, many of whom were a 
part of a large research project called the International Biological Program (IBP). Contributions were made by George VanDyne, Don Jameson, George Innis, the post docs, and other scientists associated with these early models. The scientists in the IBP Grassland Biome constructed a large simulation model of a grassland that was applied to several different grassland types; this family of models was called ELM (Innis 1978).

The emphasis of these initial simulation models was on the seasonal dynamics of vegetation and animal production in range ecosystems, under different environmental conditions. Why scientists turned to the use of computer models in ecology was described as:

"For many years, ecologists have sought to understand the temporal, spatial, and structural complexities of ecological systems. Because traditional methods of analysis proved inadequate for this task, the technology of computer science was applied in the 1960s to the study of ecological systems. Thus far, computer models have been used mainly to advance ecological science." (Holcomb Research Institute 1976, page 53)

Karplus (1977) placed ecological models close to the black box end of a spectrum of mathematical models (Figure 2). 'Black box' models are those where the behavior of the system is poorly understood, and in order to model the system, many assumptions are made. 'White box' models are those where the dynamics of the system are known quantitatively. Many systems encompass the gray area between these two extremes. Obviously the more physical or mechanical the system, the closer it lies to the white box end.

\section{Spectrum of Mathematical Models}

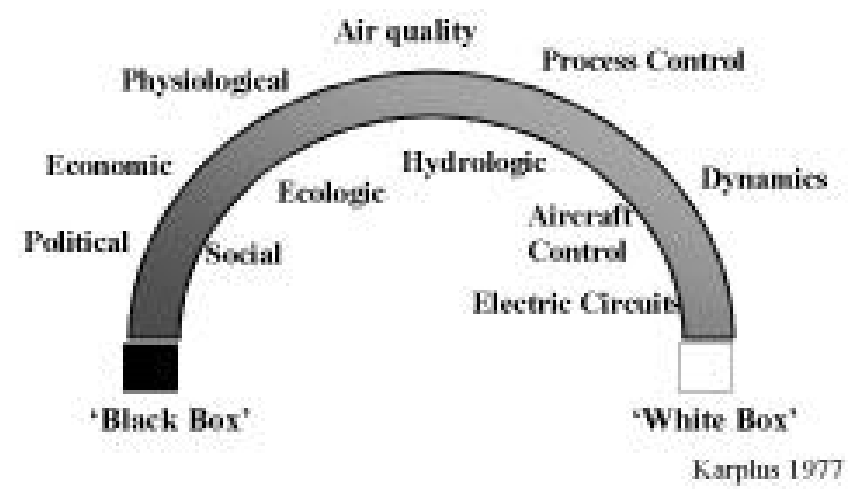

Figure. 2. The spectrum of mathematical models from the 'black box' models where the system is not well-known, to the 'white box' models where the dynamics of the system have been well-quantified (after Karplus 1977).

Within this spectrum, he also proposed the utility of models. Utility ranged from gaining insight near the black box end to product design near the white box end. Karplus concluded in 1977 that ecological models would have utility for gaining insight and testing hypotheses (Figure. 3). It was his sense that there would always be fuzziness in ecological models, and that it may be impossible to develop models that could predict

\section{Objectives of Modeling}

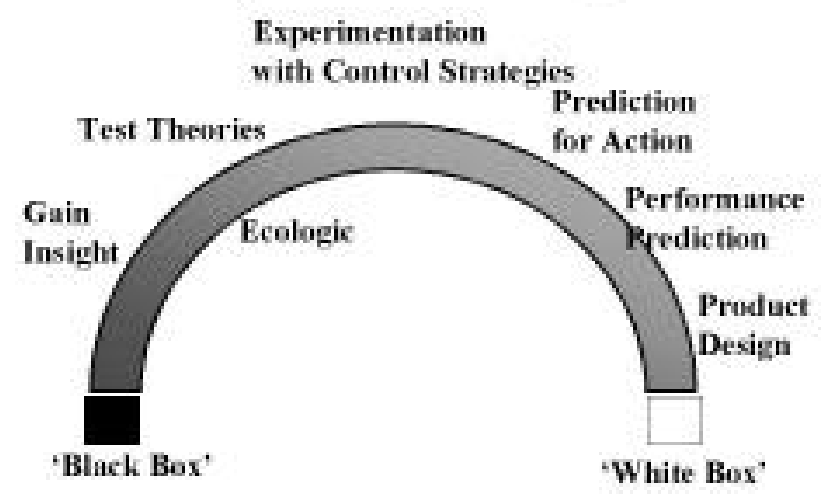

Figure. 3. The utility of models along the black box to white box spec trum (after Karplus 1977).

performance, such as plant and animal production or stocking rates - just the type of objectives needed in the management of rangeland systems. Have simulation models in range science been able to predict performance of rangeland systems and improve our understanding?

\section{Contributions of Simulation Models to Range Science}

The use of simulation models in range science continued after the Grassland Biome. Examples include the Century model from scientists at Colorado State University (Parton et al. 1987), the SPUR model from the Agricultural Research Service scientists (Hanson et al. 1992), and Savanna from a scientist at Colorado State University (Coughenour 1992). The contributions to range science have been in 3 different areas.

The first area is whole system conceptualization. To quantify range ecosystem dynamics, scientists had to conceptualize how the ecosystem works as a unit. They had to tie together ecological processes such as how environmental factors influence plant productivity, how plant productivity influences decomposition, how environmental factors influence decomposition, and how productivity and decomposition influence the nutrient cycles of the range ecosystem. This whole-system conceptualization has allowed for research questions to be posed and to be tested. It has also facilitated comparisons of ecosystem dynamics across different systems: shortgrass to tallgrass, grassland to shrubland, or North American grasslands and Australian or Asian grasslands. And these comparisons have reframed the need for field data, that is consistently collected in the same way across sites to compare the same variables. The recent move to archive vegetation productivity data for the wider scientific community would not have happened if there had not been the recognition that such data are needed to validate models and to improve our theoretical understanding of ecosystem dynamics (Scurlock et al. 1999).

The second area is improved understanding of the internal processes of an ecosystem. Scientists working with the Century model, for instance, have made significant improvements in our understanding of soil organic matter dynamics, including the role of soil texture.

The third area is improved understanding of ecosystem dynamics under disturbance. Models have been used to quantify 
the influence of disturbances such as grazing, drought, insects, and fire. Recent simulation experiments have shown that different models respond differently when water versus nutrients limit ecosystems (VEMAP members 1995) and that such differences have helped to contrast the theory underlying the models (Ryan et al. 1996, VEMAP members 1995).

As with any area of science, these contributions involved range scientists learning how to use simulation models as well as learning about the ecosystem. Many humorous stories abound about the first use of simulation models, such as a model experiment where grasshoppers gained more weight than cows. But these stories are similar to stories other scientists tell about the use of new tools in their area of research. Learning how to use the tools of simulation models has involved refining programming and mathematical skills, narrowing the scope of the models, and using rigorous experimental designs for model comparison. Over time, technological developments have also improved computer software and hardware.

Perhaps the most important contributions have resulted where modeling research has been linked with field research. Scientists associated with the Century model at Colorado State University and scientists associated with the Terrestrial Ecosystem Model at The Ecosystems Center (Massachusetts) have taken ideas and insights from their ecological models back to the field to be tested.

These contributions have value to range science. Models synthesize scientific understanding. Natural resource managers must often manipulate complicated ecological systems in highly variable climates. Could models have utility to natural resource management?

\section{Contributions of Simulation Models to Range Management}

The Holcomb Research Institute evaluated the utility of environmental models in decision-making by using a two-way classification that describes environmental models along a decision-making axis-day-to-day, short-term, and long-termand along a complexity and predictability axis (Figure 4). This

\begin{tabular}{lllll} 
& \multicolumn{3}{c}{ Type of System } & \multicolumn{2}{c}{ Unpredictable } \\
$\begin{array}{l}\text { Type of } \\
\text { Decision }\end{array}$ & Simple & Complex & Simple & Complex \\
$\begin{array}{l}\text { Day-to- } \\
\text { day }\end{array}$ & $\begin{array}{l}\text { Traffic } \\
\text { Light }\end{array}$ & $\begin{array}{l}\text { Moon } \\
\text { flight } \\
\text { models }\end{array}$ & $\begin{array}{l}\text { Personnel } \\
\text { development }\end{array}$ & $\begin{array}{l}\text { Economic } \\
\text { response to } \\
\text { tax changes }\end{array}$ \\
Models & Flood & System & Urban \\
Short- & Highway & control & response to & planning \\
decision & design & nodural & \\
making & & models & disasters & \\
$\begin{array}{l}\text { Long- } \\
\text { term }\end{array}$ & N/A & Pollution & National & Global \\
Planning & & control & budgets & environ- \\
Policy & & strategies & & $\begin{array}{l}\text { mental } \\
\text { policy }\end{array}$
\end{tabular}

Figure. 4. The environmental decision-making classification developed by the Holcomb Research Institute (1976). classification of models seems relevant here because range research is strongly oriented to understanding range ecosystems for the purpose of managing them more appropriately.

In this classification, day-to-day and short-term decision making encompass problem-specific types of technical decisions. The impact of the decision is local; examples include reservoir water release rates and insecticide spray schedules. Planning or policy making involves longer-range decisions, such as pollution standards, or the authorization of the use of a pesticide.

Predictability in their sense has two aspects: 1) the system is inherently unpredictable, or 2) the system is currently unpredictable but future additional scientific information may allow the response to be predicted.

Their examples of environmental modeling encompass physical, biological, and socio-economic models (Figure 4). Traffic models are simple systems relative to moon flight models, but as the physics is known, both are predictable systems. Unpredictable systems are characterized by personnel deployment, in this case police to fight crime. Crime is difficult to predict, but deploying personnel relatively simple, once the level of crime is known. Highway design or flood control models exemplify short-term decision-making while pollution control strategies and global environmental policy require longer-term planning.

When this classification is imposed on the types of systems and decision-making in range management today, it is apparent there are few simple and predictable models of range systems (Figure 5). There may be examples in intensive agricul-

\begin{tabular}{|c|c|c|c|c|}
\hline \multicolumn{5}{|c|}{ Type of System } \\
\hline & \multicolumn{2}{|c|}{ Predictable } & \multicolumn{2}{|c|}{ Unpredictable } \\
\hline $\begin{array}{l}\text { Type of } \\
\text { Decision }\end{array}$ & Simple & Complex & Simple & Complex \\
\hline $\begin{array}{l}\text { Day-to- } \\
\text { day }\end{array}$ & & $\begin{array}{l}\text { Fire } \\
\text { Behavior } \\
\text { Models }\end{array}$ & & $\begin{array}{l}\text { Invasive } \\
\text { species } \\
\text { dynamics }\end{array}$ \\
\hline $\begin{array}{l}\text { Short- } \\
\text { term } \\
\text { decisions }\end{array}$ & $\begin{array}{l}\text { Productivity } \\
\text { models } \\
\text { based on } \\
\text { weather }\end{array}$ & $\begin{array}{l}\text { Weather } \\
\text { forecasting } \\
\text { models } \\
\text {--short-term }\end{array}$ & $\begin{array}{l}\text { Seasonal } \\
\text { stocking } \\
\text { rate } \\
\text { decisions }\end{array}$ & $\begin{array}{l}\text { Wildlife- } \\
\text { livestock } \\
\text { interactions }\end{array}$ \\
\hline $\begin{array}{l}\text { Long- } \\
\text { term } \\
\text { Planning }\end{array}$ & N/A & $\begin{array}{l}\text { Grazing } \\
\text { systems }\end{array}$ & $\begin{array}{l}\text { State and } \\
\text { transition } \\
\text { succession- } \\
\text { al models }\end{array}$ & $\begin{array}{l}\text { Plant and } \\
\text { animal } \\
\text { productivity } \\
\text { models }\end{array}$ \\
\hline
\end{tabular}

\section{Figure. 5. Models in range science today as classified using the envi- ronmental decision-making classification of the Holcomb Research Institute.}

ture where day-to-day simple systems have been modeled, for example hog confinement operations, but few operations in range management are as tightly controlled and predictable. Ecological systems tend to be complex with a strong element of chaotic behavior.

Simulation models have been used to analyze a variety of site-specific range management problems: grazing management alternatives, climatic patterns on grassland production, cloud seeding for hail suppression, drought, strip-mine reclamation, grazing and fire management, grasshopper outbreaks 
(Parton et al. 1994). As the technology and data became available to analyze larger geographic areas, simulation models have been used to look at regional issues such as climate change within the Great Plains (Parton et al. 1994).

The importance of linking ecological responses to economic decisions has long been recognized in range science. In the late 1970s, the Regional Economic Resource Simulation Model, an integrated social-economic-ecological model, examined the influence of investments (including ranching) on the regional economy. As quantitative information increased, opportunities to link this ecological information with social or economic models have improved (Conner 1994). Decisionmaking within ranch enterprises was the focus of the model developed by Stafford-Smith and Foran (1990). Economics was also included in the study to look at the potential impact of climatic change on plant and animal production (Hanson et al 1992).

Over 20 years ago, the Holcomb Research Institute identified concerns about the use of ecological simulation models in natural resource issues: 1) too much detail in research models, and 2) the optimal solution not identified. They went on to describe institutional problems: Ecological theory is incomplete. Data are lacking for model validation. Models developed in research are often not appropriate for the applied problems. And lastly, the decision-makers are not familiar with ecological modeling and cannot make use of these tools. Have things changed since 1976 ?

\section{Applying Simulation Models to Natural Resource Issues}

Here are what I believe are today's institutional problems of applying models to natural resource problems.

First, managers are uneasy about ecological theory. Can a box and arrow diagram of an ecological model convey to decision-makers what scientists know and what they assume within these models? Can all of the relationships be tied back to field research studies? What are critical assumptions that influence the behavior of the models? Lack of good communication creates an unease about the underlying theory in the model.

Secondly, we still lack data for validation. The state-andtransition models appear to offer valuable insights with respect to the successional dynamics of rangeland ecosystems, particularly those that are subject to episodic events. By our own accounting however, we do not have sufficient data on rangeland ecosystems recovering from disturbance. We lack the field data to estimate transition parameters in these models and to evaluate model predictions.

Thirdly, decision-makers are still unfamiliar with ecological modeling. However, this problem is often the result of some significant differences (Table 1) between the research culture and the management culture (USDA Forest Service 1997). The time horizons are often long in research, whereas management decisions need to be made within specific (often short) timeframes. Research seeks to generalize, whereas decision-makers have a locally specific need. In research, critique is key-the nature of science is a running argument. In management, the answer is needed. Assumptions must be explicit in research to test hypotheses, whereas assumptions may not be entirely known by all parties in the decision-making
Table 1. Differences Between Research and Decision Making

\begin{tabular}{ll} 
Research Culture & Management Culture \\
\hline Time horizons long & Time horizons short \\
Generalization & Locally specific \\
A running argument & The answer \\
Assumptions explicit & Assumptions not always known \\
Context is science & $\begin{array}{c}\text { Science is one element in the } \\
\text { decision space }\end{array}$ \\
Results given as probabilities & Results needed in the context of \\
& acceptable risks \\
\hline
\end{tabular}

process. Science is often only one element in the decision space for managers. In research, the context is science. And lastly, research draws conclusions in terms of probabilities whereas decision-makers look at options in terms of acceptable risks. These differences are critical in developing ways to apply simulation models in natural resource problems.

And fourthly, there is the aspect of 'uncertainty about uncertainty' in models. A model may reflect state-of-the-art theory in an area of range science, but may not yet contain a complete understanding of the ecological processes within a single ecosystem, or reflect the dynamics of the diversity of range ecosystems. This degree of uncertainty needs to be explicitly identified by the scientists and understood by the manager. Science, and models in particular, can guide policy makers as they make the tough policy choices that require balancing competing interests. The gap between the model results and the management decisions, the gap between science and management, needs to be negotiated carefully because it influences the credibility of models and science in natural resource management.

\section{Models Likely to Remain Important in Improving our Understanding of Rangeland Ecosystems}

Understanding is an objectively determined, empirical match between some set of confirmable, observable phenomena in the natural world and a conceptual construct (Pickett et al 1994). Models offer that conceptual construct, and are likely to remain a very important aspect of improving our understanding of the dynamics of rangeland ecosystems.

\section{References}

Connor, J. R. 1994. Assessing the socio-economic impacts of climate change on grazing lands. Presentation at Workshop on Integrated Assessments of the Impacts of Climate Change on Natural Resources, San Diego, California, February 28-March 2, 1993.

Coughnour, M. B. 1992. Spatial modeling and landscape characterization of an African pastoral ecosystem: a prototype model and its potential use for monitoring drought. In Ecological Indicators Vol. 1. Pages 787-810. Edited by D. H. McKenzie, D. E. Hyatt, and V. J. McDonald, Elsevier Applied Science, New York.

Hanson, J. D., B. B. Baker, and R. M. Bourdon. 1992. The effect of climate change on rangeland livestock production: a theoretical approach Agricultural Systems. 
Holcomb Research Institute. 1976. Environmental modeling and decision making. The United States Experience. A report by the Holcomb Research Institute, Butler University for the Scientific Committee on Problems of the Environment. Praeger Publishers, New York.

Innis, G. (ed.) 1978. Grassland Ecosystem Model. Ecological Studies 26. Springer-Verlag, New York, 298 pages.

Karplus, Walter J. 1977. The place of systems ecology models in the spectrum of mathematical models. IN: New Direction in the analysis of ecological systems, edited by G. S. Innis. Simulation Council Proceedings Series, Volume 5, Number 2. December 1975. The Society for Computer Simulation (Simulation Councils, Inc): La Jolla, Calif. page 225-228

Parton, W.J., D.S. Schimel, C.V Cole, and D.S. Ojima. 1987. Analysis of factors controlling soil organic matter levels in Great Plains grasslands. Soil Sci. Soc. Amer. J. 51:1173-1179

Parton, W. J., D. S. Ojima, D. S. Schimel. 1994. Environmental change in grasslands: assessment using models. Climatic Change 28:111-141.

Pickett, S. T. A., J. Kolasa, C.G. Jones. 1994. Ecological Understanding. Academic Press, Inc.
Ryan, M.G., E.R. Hunt, Jr., R.E. McMurtrie, G.I. Agren, J.D. Aber, A.D. Friend, E.B. Rastetter, W.M. Pulliam, R.J. Raison, and S. Linder. 1996. Comparing models of ecosystem function for temperate conifer forests. I. Model description and validation. In: Global Change: Effects on Coniferous Forests and Grasslands. A. I. Breymeyer, D. O. Hall, J. M. Melillo, And G. I. Agren, (editors). John Wiley and Sons Ltd.

Scurlock, J. M.O., R.J. Olson, W.J. Parton, and S.D. Prince. 1999. Terrestrial NPP: toward a consistent data set for global model evaluation. Ecological Applications 9: 913-919.

USDA Forest Service. 1997. Integrating science and decisionmaking: guidelines for collaboration among managers and researchers in the Forest Service. FS-608. Washington, DC: US Government Printing Office.

Volesky, J.D., Schacht, W.H., and P.E. Reece. 1999. Leaf area, visual obstruction, and standing crop relationships on Sandhills rangeland. J of Range Management 52:494-499.

Project Leader, Rocky Mountain Research Station, 240 West Prospect, Fort Collins, CO 80526, Invited Presentation, Symposium: Science: Perspectives for Natural Resource managers, Sponsored by the Western Land Grant Universities and WCC40, Annual Meeting, Society of Range Management, February 15, 2000.

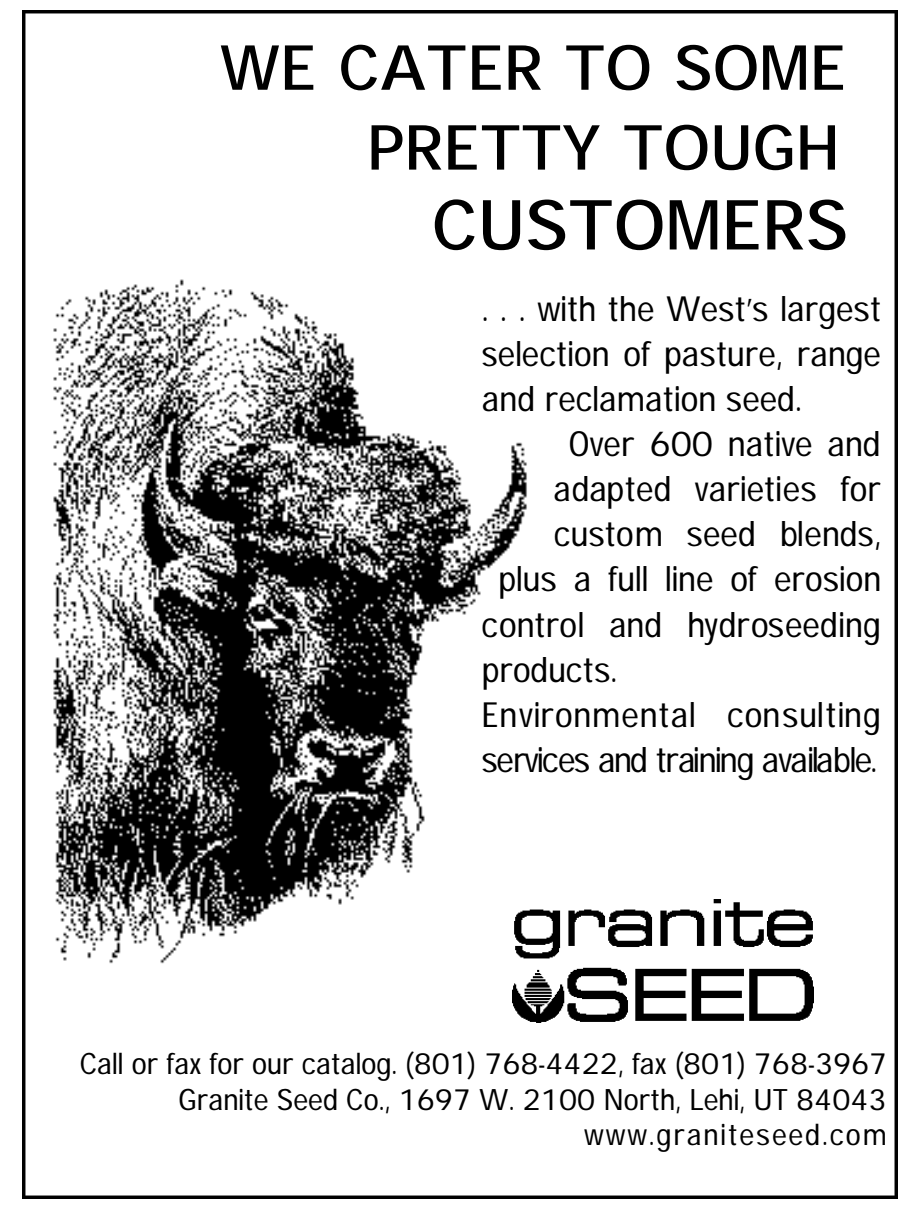

